\title{
A study of plasma sodium levels in elderly people taking amiloride or triamterene in combination with hydrochlorothiazide
}

\author{
H.M. Fidler, J. Goldman, C.A. Bielawska, G.S. Rai and B.I. Hoffbrand ${ }^{1}$
}

Department of Care of the Elderly, and the ${ }^{1}$ Department of Medicine, Whittington Hospital, Highgate Hill, London N19 $5 N F, U K$

\begin{abstract}
Summary: This study was performed to compare the effect of one month's treatment with hydrochlorothiazide $(25 \mathrm{mg})$ in combination with either amiloride $(2.5 \mathrm{mg})$ or triamterene $(50 \mathrm{mg})$ on plasma sodium levels in elderly people in institutional care. Fifty residents of NHS nursing or social service residential care established on diuretics for congestive cardiac failure and aged 64 years or over were recruited. Forty-one patients were included in the final data analysis. Patients on hydrochlorothiazide/ amiloride had a significantly lower plasma sodium (137 vs $139 \mathrm{mmol} / \mathrm{l}, 95 \%$ confidence interval for difference between medians $0-2 \mathrm{mmol} / \mathrm{l})$ than those on hydrochlorthiazide/triamterene $(P=0.01)$. In equivalent potassium-retaining doses, amiloride is associated with significantly lower plasma sodium levels than triamterene, when given in combination with hydrochlorothiazide in elderly patients with congestive cardiac failure. This finding adds weight to uncontrolled observations implicating thiazide/amiloride diuretic combinations in causing serious hyponatraemia. This danger, although uncommon, should perhaps influence prescribing habits in an at-risk population.
\end{abstract}

\section{Introduction}

There is considerable uncontrolled evidence that amiloride-containing thiazide diuretic combinations are especially liable to give rise to serious diuretic-related hyponatraemia. ${ }^{1-3}$ It is unclear whether this is due to greater usage of such preparations than other potassium-retaining diuretic combinations or to a specific effect of amiloride. We have therefore conducted a single blind cross-over study comparing amiloride to triamterene in equivalent potassium-retaining doses in combination with hydrochlorothiazide in elderly people requiring diuretic treatment.

\section{Subjects}

Fifty elderly people under continuing care in long-stay hospital beds or social service residential accommodation were initially recruited. They were already on maintenance diuretic therapy for congestive cardiac failure as prescribed by their general practitioner or geriatrician. To be eligible for entry patients were in a stable clinical condition and were not taking a diuretic dosage greater than $80 \mathrm{mg}$

Correspondence: H.M. Fidler, M.R.C.P., University College London Medical School, Department of Medical Microbiology, 1st Floor, School of Pathology, 67-71 Riding House Street, London W1P 7PP, UK.

Accepted: 27 May 1993 frusemide or equivalent or other drugs associated with hyponatraemia. At the initial visit, informed written consent was obtained from each subject, or from their next of kin if there was cognitive impairment which affected their full understanding of the project. Ethical committee approval was obtained prior to study commencement.

\section{Methods}

Clinical examination was performed to confirm adequate treatment of congestive cardiac failure at entry, and at monthly intervals during the trial. Blood and spot urine samples were taken and the diuretic at entry to the study recorded. This was replaced by hydrochlorothiazide $25 \mathrm{mg} /$ day for a wash-out period of one month, after which a further urine and blood sample was taken and patients were randomized to receive either: (a) hydrochlorothiazide $(25 \mathrm{mg}) /$ amiloride $(2.5 \mathrm{mg})$ (HCTZ/A) for one month followed by hydrochlorothiazide $(25 \mathrm{mg}) /$ triamterene $(50 \mathrm{mg})(\mathrm{HCTZ} / \mathrm{T})$ for one month; or (b) hydrochlorothiazide ( $25 \mathrm{mg})$ / triamterene $(50 \mathrm{mg})(\mathrm{HCTZ} / \mathrm{T})$ for one month followed by hydrochlorothiazide $(25 \mathrm{mg})$ /amiloride $(2.5 \mathrm{mg})(\mathrm{HCTZ} / \mathrm{A})$ for one month.

Further blood and urine samples were taken after each month of the cross-over periods, and at the end of the study patients were given their 
diuretic at study entry. Blood samples were analysed for plasma electrolytes, urea, creatinine, magnesium, osmolality, liver function, glucose, urate and haematocrit. Spot urine samples were analysed for sodium, potassium and magnesium. Plasma electrolytes were measured using a Technicon FMA2 autoanalyser, plasma osmolality using an advanced osmometer (Vital Scientific) and haematocrit in a Technicon $\mathrm{H} 1$ analyser. Full compliance data were collected by a tablet count for the first month of the cross-over phase, and a patient who had taken $>75 \%$ of her/his medication for that month was judged compliant.

\section{Statistical analysis}

The study was designed to detect a $2 \mathrm{mmol} / \mathrm{l}$ difference in serum sodium with 25 patients in each group, testing at the $5 \%$ level of significance with $90 \%$ power. Due to non-Gaussian scatter of results, a non-parametric two period cross-over analysis of variance was performed on laboratory values on an intention to treat basis using the Wilcoxon rank sum test. ${ }^{4} \mathrm{~A}$ probability of less than 0.05 was taken as statistically significant.

\section{Results}

Nine patients did not complete the protocol and 41 were therefore included in the cross-over analysis. Of these, eight were in long-stay homes and 33 were in part 3 homes. All patients except one of the latter group were compliant. Thirty-two patients were female and the mean age was 84 years with a range of 64-107 years. Thirteen patients received HCTZ/A followed by HCTZ/T and 28 received
HCTZ/T followed by HCTZ/A due to researcher error in randomization. Thus, although each patient received both treatments, unfortunately more patients received HCTZ/T first. Using the $\stackrel{\varrho}{\llcorner}$ statistical method described, a comparison was made for all results depending on the order given in practice. ${ }^{4} \mathrm{~A}$ possible interaction between treat-o ments and periods that might confound results was $\underline{\underline{O}}$ only found for plasma osmolality and urine $\frac{\bar{\rho}}{\bar{D}}$ magnesium and therefore these data were rejected.

At entry, 31/50 (62\%) of the patients were taking frusemide/amiloride and most of the remainder ${ }^{\mathrm{s}}$ were on frusemide $6 / 50(12 \%)$, bumetanide plus. potassium $5 / 50(10 \%)$, or cyclopenthiazide plus $\overrightarrow{\vec{\omega}}$ potassium $4 / 50(8 \%)$. Of the nine patients who did not complete the full 4 month protocol, three were withdrawn due to cardiac problems (myocardial 3 . infarction, congestive cardiac failure and complete heart block, one each). Three became confused and ${ }_{\circ}$ compliance fell to $<75 \%$, one developed acute on $\vec{\sigma}$ chronic renal failure and two died suddenly of $\widehat{c}$ presumed cardiac causes. The grouped data are $v$ given in Table I.

A statistically significant difference $(P=0.01, \rightarrow$ $95 \%$ confidence interval for difference in medians $=0$ 0-2 mmol/l) was found between the two treatment 0 groups with respect to plasma sodium only. The median sodium level for HCTZ/T was 139 mmot/ $l_{\vec{\bullet}}$ compared to $137 \mathrm{mmol} / 1$ in the HCTZ/A phase. Plasma sodium values of less than $130 \mathrm{mmol} / 1$ wege recorded in only four patients; one whilst takimg hydrochlorothiazide, two on HCTZ/A only (127 mmol/l) and one on both HCTZ/T and HCTZ/A흐 $(127 \mathrm{mmol} / 1$ and $126 \mathrm{mmol} / 1$, respectively). Although there was a trend toward lower plasma $\triangle$ urate levels in the HCTZ/A phase, this did not $\overrightarrow{\vec{O}}$ reach statistical significance $(P=0.10)$.

Although the median plasma potassium level

Table I Median plasma values (with range in parentheses) after each one month treatment period for 41 patients with congestive cardiac failure

\begin{tabular}{|c|c|c|c|c|}
\hline & $H C T Z$ & $H C T Z / T$ & $H C T Z / A$ & $\underset{\text { value* }}{\mathrm{P}}$ \\
\hline $\begin{array}{l}\text { Sodium } \\
(\mathrm{mmol} / \mathrm{l})\end{array}$ & $\begin{array}{c}138 \\
(132-141)\end{array}$ & $\begin{array}{c}139 \\
(127-143)\end{array}$ & $\begin{array}{c}137 \\
(126-143)\end{array}$ & 0.01 \\
\hline $\begin{array}{l}\text { Potassium } \\
(\mathrm{mmol} / \mathrm{l})\end{array}$ & $\begin{array}{c}3.5 \\
(2.9-6.0)\end{array}$ & $\begin{array}{c}3.8 \\
(2.7-5.5)\end{array}$ & $\begin{array}{c}3.9 \\
(3.1-5.5)\end{array}$ & 0.29 \\
\hline Haematocrit & $\begin{array}{c}0.37 \\
(0.24-0.46)\end{array}$ & $\begin{array}{c}0.38 \\
(0.27-0.44)\end{array}$ & $\begin{array}{c}0.37 \\
(0.26-0.42)\end{array}$ & 0.99 \\
\hline $\begin{array}{l}\text { Urate } \\
(\mathrm{mmol} / \mathrm{l})\end{array}$ & $\begin{array}{c}0.37 \\
(0.19-0.54)\end{array}$ & $\begin{array}{c}0.40 \\
(0.29-0.53)\end{array}$ & $\begin{array}{c}0.37 \\
(0.22-0.66)\end{array}$ & 0.10 \\
\hline $\begin{array}{l}\text { Urea } \\
(\mathrm{mmol} / \mathrm{l})\end{array}$ & $\begin{array}{c}6.6 \\
(3.2-22.7)\end{array}$ & $\begin{array}{c}9.2 \\
(4.8-20.7)\end{array}$ & $\begin{array}{c}8.5 \\
(4.8-29.7)\end{array}$ & 0.63 \\
\hline $\begin{array}{l}\text { Magnesium } \\
(\mathrm{mmol} / \mathrm{l})\end{array}$ & $\begin{array}{c}0.86 \\
(0.53-1.17)\end{array}$ & $\begin{array}{c}0.91 \\
(0.66-1.07)\end{array}$ & $\begin{array}{c}0.92 \\
(0.7-1.27)\end{array}$ & 0.18 \\
\hline
\end{tabular}

*Probability for HCTZ/T vs HCTZ/A. 
suggested that, in the wash-out period, hydrochlorothiazide alone caused only a small drop from baseline, no fewer than $55 \%$ of subjects actually had a value of less than $3.2 \mathrm{mmol} / \mathrm{l}$. On HCTZ/T this percentage fell to $18 \%$ and to $7 \%$ on HCTZ/A for the same period.

\section{Discussion}

We believe that this is the first study designed to test the hypothesis that amiloride is more liable than triamterene to lower plasma sodium levels in combination with hydrochlorothiazide. The statistically significantly lower median plasma sodium level in the amiloride-treated patients is, although not in itself clinically important, probable confirmatory evidence that amiloride is more prone to induce serious hyponatraemia than triamterene in the doses used.

In a study comparing identical doses of $\mathrm{HCTZ} / \mathrm{A}$ and HCTZ/T to our own in elderly patients with congestive cardiac failure ${ }^{5}$ both preparations were equally effective and well tolerated. The authors, however, record a significantly $(P=0.05)$ lower value for serum sodium of $2 \mathrm{mmol} / \mathrm{l}$, identical to our own findings in patients on the HCTZ/A combination. They do not, however, refer to its possible significance in relation to clinically significant diuretic-induced hyponatraemia. In view of the relative rarity of serious hyponatraemia on these preparations, neither our study nor that of Ghosh and colleagues ${ }^{5}$ had the power to distin- guish between the diuretic combinations in terms of clinically significant hyponatraemia.

The mechanism of diuretic-induced hyponatraemia is not precisely known. ${ }^{6}$ However, amiloride in contrast to triamterene may have the property of reducing renal tubular water loss, ${ }^{7}$ and this may be the mechanism whereby it ameliorates the polyuria of chronic lithium treatment. ${ }^{8}$ This effect may form the basis of the biochemical changes noted.

Diuretic-induced hyponatraemia appear to be especially likely to occur in elderly women, ${ }^{2}$ who comprised a majority of the population we studied. Both HCTZ/T and HCTZ/A in the doses we studied have been used in large trials of the treatment of hypertension in the elderly and shown to be effective in stroke and heart disease prevention. No case of serious hyponatraemia was reported in either study. ${ }^{9,10}$ However, the accumulating evidence that amiloride may be especially prone to induce hyponatraemia when used with a thiazide diuretic should be considered when choosing a potassium-sparing combination in patients at risk of serious hyponatraemia.

\section{Acknowledgements}

We would like to thank Dr Sheena McFarlane for chemical pathology advice and organization, Professor Ariel Lant for advice on the study protocol and Wendy Godwin at SmithKline Beecham for support.

\section{References}

1. Sunderam, S.G. \& Mankikar, G.D. Hyponatraemia in the elderly. Age Ageing 1983, 12: 77-80.

2. Mathew, T.H., Boyd, I.W. \& Rohan, A.P. Hyponatraemia due to the combination of hydrochlorothiazede and amiloride (Moduretic): Australian Spontaneous Reports 1977-1988. Med J Austr 1990, 152: 308-309.

3. Bayer, A.J., Farag, R., Browne, S. \& Pathy, M.S.J. Plasma electrolytes in elderly patients taking fixed combination diuretics. Postgrad Med J 1986, 62: 159-162.

4. Jones, B. \& Kenwood, M.G. Design and Analysis of Crossover Trials. Monograph Statist Appl Prob 1989, Vol. 34, Chapman and Hall, London, 1989.

5. Ghosh, A.K., Mankikar, G., Strouthidis, T., Windsor, A., Long, C. \& Glover, D.R. A single-blind, comparative study of hydrochlorothiazide/amiloride ('Moduret' 25) and hydrochlorothiazide/triamterene ('Dyazide') in elderly patients with congestive heart failure. Curr Med Res Opin 1987, 10: 573-579.

6. Byatt, C.M., Millard, P.H. \& Levin, G.E. Diuretics and electrolyte disturbances in 1000 consecutive geriatric admissions. J R Soc Med 1990, 83: 704-708.

7. Scoble, J.E., Sweny, P., Varghese, Z. \& Moorhead, J. Renal physiology revisited: amiloride. Lancet 1986, ii: 326-328.

8. Battle, D.C., von Roitte, A., Gavira, M. \& Grupp, M. Amelioration of polyuria by amiloride in patients receiving long-term lithium therapy. N Engl J Med 1985, 312: 408-414.

9. The European Working Party on High Blood Pressure in the Elderley (EWPHE). Antihypertensive therapy in elderly patients. Neth J Med 1984, 27: 165-170.

10. The Medical Research Council Working Party. MRC trial of treatment of hypertension i.. older patients. Preliminary results. Br Med J 1992, 304: 405. 